\title{
Chemokine Expression Profile
}

National Cancer Institute

\section{Source}

National Cancer Institute. Chemokine Expression Profile. NCI Thesaurus. Code C129894.

The identification and quantitation of all of the chemokines expressed in a biological sample. 